\title{
Diastolic function is associated with quality of life and exercise capacity in stable heart failure patients with reduced ejection fraction
}

\author{
M.F. Bussoni, G.N. Guirado, M.G. Roscani, B.F. Polegato, L.S. Matsubara, \\ S.G.Z. Bazan and B.B. Matsubara
}

Departamento de Clínica Médica, Faculdade de Medicina de Botucatu, Universidade Estadual Paulista, Botucatu, SP, Brasil

\begin{abstract}
Exercise capacity and quality of life (QOL) are important outcome predictors in patients with systolic heart failure (HF), independent of left ventricular (LV) ejection fraction (LVEF). LV diastolic function has been shown to be a better predictor of aerobic exercise capacity in patients with systolic dysfunction and a New York Heart Association (NYHA) classification $\geqslant I I$. We hypothesized that the currently used index of diastolic function E/e' is associated with exercise capacity and QOL, even in optimally treated HF patients with reduced LVEF. This prospective study included 44 consecutive patients aged $55 \pm 11$ years (27 men and 17 women), with LVEF $<0.50$ and NYHA functional class I-III, receiving optimal pharmacological treatment and in a stable clinical condition, as shown by the absence of dyspnea exacerbation for at least 3 months. All patients had conventional transthoracic echocardiography and answered the Minnesota Living with HF Questionnaire, followed by the 6-min walk test (6MWT). In a multivariable model with 6MWT as the dependent variable, age and E/e' explained $27 \%$ of the walked distance in $6 \mathrm{MWT}(\mathrm{P}=0.002$; multivariate regression analysis). No association was found between walk distance and LVEF or mitral annulus systolic velocity. Only normalized left atrium volume, a sensitive index of diastolic function, was associated with decreased QOL. Despite the small number of patients included, this study offers evidence that diastolic function is associated with physical capacity and QOL and should be considered along with ejection fraction in patients with compensated systolic HF.
\end{abstract}

Key words: Echocardiography; Left ventricular dysfunction; Six-minute walk test; Dyspnea

\section{Introduction}

Heart failure (HF) is a leading cause of death in many countries (1). Mortality is as high as $80 \%$ in the 5 -year period following the first decompensation event $(2,3)$. Exercise intolerance and decreased quality of life have been demonstrated to be markers of poor prognosis in these patients, independent of left ventricular (LV) ejection fraction (LVEF) (4-7).

Evidence indicates that exercise capacity and quality of life are related to LV filling pressure, mainly for patients with diastolic $\mathrm{HF}$, that is, those with an LVEF $>0.50(8,9)$. It has been suggested that, when the LVEF is low, the resulting symptoms are related to both systolic and diastolic dysfunction (10). LV early diastolic function has been shown to be a better predictor of aerobic exercise capacity in patients with systolic dysfunction and a New York Heart Association (NYHA) classification I-III (11-13). On the other hand, the effect of diastolic function on quality of life in compensated patients with LV systolic dysfunction has not been fully addressed. During the last decade, the assessment of diastolic function has been enhanced by the use of tissue Doppler-derived indexes in combination with normalized left atrial volume (LAV) (14).

Therefore, assuming that HF symptoms are greatly affected by LV diastolic pressure filling $(15,16)$, we hypothesized that exercise intolerance and decreased quality of life can be predicted by diastolic function indexes in stable HF patients with reduced LVEF. To address this question, the aim of this study was to analyze the association of both systolic and diastolic LV function with the quality of life and exercise tolerance in these patients.

\section{Material and Methods}

\section{Study design and population}

This prospective study included 44 consecutive patients over 18 years of age (age range, $55 \pm 11$ years;

Correspondence: M.F. Bussoni, Departamento de Clínica Médica, Faculdade de Medicina de Botucatu, UNESP, Rubião Júnior, s/n, 18618-000 Botucatu, SP, Brasil. Fax: +55-14-3882-2238. E-mail: marjory.bussoni@yahoo.com.br 
27 men and 17 women) who were treated in the Ambulatório de Insuficiência Cardíaca of our institution for HF and reduced LVEF. The inclusion criteria were as follows: men and women with functional class I-III according to the NYHA classification, a stable clinical condition shown by the absence of dyspnea exacerbation for at least 3 months, LVEF less than 0.5 , and ability to cooperate and understand the information they were given.

Patients with any of the following conditions were excluded: HF due to primary valve disease, chest pain or unstable angina, high blood pressure, acute dyspnea, cardiac arrhythmias, clinically manifested pulmonary diseases, more than mild valve dysfunction, orthopedic disease, physical limitation, or signs of infection.

The procedures were approved by the Ethics Committee of the Faculdade de Medicina de Botucatu (OF.405/2009-CEP) and were conducted in accordance with the Declaration of Helsinki. All participants gave written informed consent.

\section{Study protocol}

Clinical evaluation. Gender, age, comorbidities (diabetes mellitus, obesity/overweight, dyslipidemia, thyroid dysfunction, and renal failure), tobacco use, symptoms, and pharmacological treatments were recorded. Blood pressure and heart rate were determined as the average of three replicate measurements after at least 10 min of rest in a supine position.

Echocardiography. Immediately after clinical evaluation, all exams were performed by the same cardiologist (SGZB), following standard procedures for recording images and making measurements $(17,18)$. The ultrasound equipment used was a Philips HDI5000 (USA). LV mass was estimated from linear dimensions as follows: $L V$ mass $(\mathrm{g})=0.8 X\left\{1.04\left[(\mathrm{LVDd}+\mathrm{PWTd}+\mathrm{SWTd})^{3}-\right.\right.$ $\left.\left.(\text { LVDd })^{3}\right]\right\}+0.6$, where LVDd, PWTd, and SWTd represent diastolic $L V$ diameter, posterior wall thickness, and septal wall thickness, respectively. LV mass was indexed for body surface area $\left(\mathrm{g} / \mathrm{m}^{2}\right)$. LV systolic function was assessed by LVEF using the modified Simpson's rule and tissue Doppler-derived average systolic mitral annular motion ( $\mathrm{S}^{\prime}, \mathrm{cm} / \mathrm{s}$ ). Diastolic function was evaluated using pulsed Doppler recordings of mitral inflow velocities $E$ and A waves $(\mathrm{cm} / \mathrm{s})$, deceleration time $(\mathrm{ms})$, isovolumic relaxation time (ms), LAV normalized to body surface area $\left(\mathrm{LAVI}, \mathrm{mL} / \mathrm{m}^{2}\right)$, as well as tissue Doppler-derived average diastolic mitral annular motion (e', cm/s) and the E/ e' ratio. The variable e' was analyzed as the average of the medial and lateral annulus motion.

Minnesota Living with Heart Failure Questionnaire (MLWHFQ). In a quiet and private place, all participants answered the 21 questions related to symptoms and physical and psychosocial functions with respect to the impact of the disease on his/her life in the previous month. The total score ranges from 0 (optimal) to 105 (extremely poor) points $(19,20)$.
Six-minute walk test (6MWT). Each patient performed the test, following the recommendations of the American Thoracic Society (21). The participants were asked to walk as fast as they could for $6 \mathrm{~min}$, with the option to interrupt the test at any time. Standardized motivational comments were made at 1-min intervals during the walk. The test course was $30 \mathrm{~m}$ long, with markers every $3 \mathrm{~m}$. The final result was the total distance walked, in meters, during the established time. The same researcher carried out the 6MWT and MLWHFQ.

\section{Statistical analysis}

Data management and analysis were performed using SYSTAT 12.0 (SYSTAT Software, Inc., USA). Summary data are reported as means $\pm S D$, unless otherwise specified. Linear regression was used to predict distance walked during the 6MWT and MLWHFQ scores. Independent variables included in the univariate model were gender, age, body surface area, left chamber dimensions, and LV systolic and diastolic function indexes. Significant associations indicated by simple linear regression were included in the multivariate linear regression. Colinearity was avoided by removing from the model those variables with a significant correlation coefficient and selecting those with the greatest clinical relevance. Pearson's correlation was used to analyze the association between LV systolic function indexes and E/e'. The level of significance was set at $\mathrm{P}<0.05$.

\section{Results}

\section{Patients}

Of the 195 patients who visited the Ambulatório de Insuficiência Cardíaca, Hospital das Clínicas de Botucatu, from January 2008 to January 2010, 151 presented one or more of the exclusion criteria; therefore, 44 patients (27 men and 17 women) were finally included in the study.

Underlying causes of HF and characteristics of the study population are presented in Table 1. Myocardial ischemia was the cause of ventricular dysfunction in $22.7 \%$ of the population (10 cases). Twelve patients presented hypertensive heart disease, 11 dilated cardiomyopathy, 8 Chagas' disease, and the remaining $3 \mathrm{HF}$ due to other causes. At the time of entry into the study, 19 patients had no other disease leading to HF, 19 presented one comorbidity, and 6 presented two or more comorbidities. Ten individuals reported tobacco use.

The average age was $55 \pm 11$ years, and the average body mass index was $26 \pm 5 \mathrm{~kg} / \mathrm{m}^{2}$. The average myocardial mass $\left(155 \pm 41.8 \mathrm{~g} / \mathrm{m}^{2}\right)$, LV diastolic and systolic diameters $(6.4 \pm 0.85$ and $5.2 \pm 0.93 \mathrm{~cm}$, respectively), and LAVI $\left(54 \pm 15.8 \mathrm{~mL} / \mathrm{m}^{2}\right)$ were all increased above normal values. The LVEF (36 $\pm 8 \%$ ) was below $30 \%$ in 12 patients. The average $6 \mathrm{MWT}$ distance was $444 \pm 63.7 \mathrm{~m}$, and the average MLWHFQ score was $28.7 \pm 21.17$.

The cardiovascular drugs used in this population were 
Table 1. Characteristics of the study population.

\begin{tabular}{lc}
\hline Parameters & Values \\
\hline Female/male & $17 / 27$ \\
Age (years) & $55 \pm 11$ \\
Body mass index $\left(\mathrm{kg} / \mathrm{m}^{2}\right)$ & $26 \pm 5$ \\
Systolic blood pressure $(\mathrm{mmHg})$ & $125 \pm 17.2$ \\
Diastolic blood pressure $(\mathrm{mmHg})$ & $83 \pm 13.2$ \\
Heart rate (bpm) & $71 \pm 14.1$ \\
Underlying cause of heart failure $(\mathrm{n})$ & \\
Hypertensive heart disease & 12 \\
Ischemic heart disease & 10 \\
Dilated cardiomyopathy & 11 \\
Chagas' disease & 8 \\
Others & 3 \\
Comorbidities (n) & \\
Diabetes & 16 \\
Dyslipidemia & 11 \\
Hypothyroidism & 1 \\
Echocardiography & \\
LVEF (\%) & \\
LV mass (g/m ${ }^{2}$ ) & $36 \pm 8$ \\
LAVI (mL/m ${ }^{2}$ ) & $155 \pm 41.8$ \\
E (cm/s) & $54 \pm 15.8$ \\
A (cm/s) & $76 \pm 27.2$ \\
S' (cm/s) & $69 \pm 23.5$ \\
e' (cm/s) & $7.6 \pm 1.19$ \\
E/e' (cm/s) & $\pm 1.2 \pm 2.96$ \\
6MWT distance (m) & $28.7 \pm 21.17$ \\
MLWHFQ score & \\
\hline & \\
\hline
\end{tabular}

Data are reported as means $\pm S D$ or number of cases. LV: left ventricle; LVEF: LV ejection fraction; LAVI: normalized left atrium volume; S': average systolic mitral annular motion; e': average diastolic mitral annular motion; E/e': mitral inflow E velocity to tissue Doppler e' ratio; 6MWT: 6-min walk test; MLWHFQ: Minnesota Living with Heart Failure Questionnaire. oral diuretics (88.6\%), angiotensin-converting enzyme inhibitors/angiotensin II receptor blockers (95.5\%), beta blockers $(88.6 \%)$, spironolactone $(56.8 \%)$, digoxin $(56.8 \%)$, aspirin $(40.9 \%)$, statin $(29.5 \%)$, and warfarin $(11.4 \%)$.

\section{Physical capacity and quality of life}

Univariate analysis revealed that a number of variables were significantly related to distance walked (Table 2). Colinearity was found between E/e', LV mass, and LAVI; multivariate regression analysis included age and E/e'. After adjusting for age, walk distance was significantly associated with $E / e^{\prime}(P=0.015)$. LVEF and $S^{\prime}$ did not show any association with walk distance, even though these systolic function indexes were associated with $E / e^{\prime}$ (LVEF: $R=-0.583, P<0.001$, and S': $R=-0.607$, $\mathrm{P}<0.001$, Pearson's correlation). Table 3 shows that, among the continuous variables analyzed by simple linear regression, only $\mathrm{LAVI}$, an index of diastolic dysfunction, was significantly associated with the MLWHFQ score. None of the systolic function indexes was associated with quality of life. Gender, tobacco use, and diabetes did not influence either the walk distance or the quality of life of the patients.

\section{Discussion}

In the present study, it was found that diastolic function but not LVEF or tissue Doppler mitral systolic velocity was associated with exercise tolerance in patients with stable functional class I-III HF and reduced LVEF. In addition, increased LAVI but not the degree of systolic dysfunction was associated with decreased quality of life.

Although ventricular systolic/diastolic dysfunction may decrease exercise tolerance, indexes of LV systolic function have been shown to be poor predictors of exercise capacity (13), while diastolic function indexes have not been fully studied. In the last decade, several

Table 2. Estimating walking distance in reduced ejection fraction heart failure patients from age, body mass index, and echocardiography by simple linear regression.

\begin{tabular}{lcccc}
\hline Variable & Coefficient & $95 \% \mathrm{Cl}$ & $\mathrm{R}$ \\
\hline Age & -2.36 & -4.11 to -0.61 & 0.387 & 0.009 \\
BMI & -0.10 & -4.00 to 3.00 & 0.077 & 0.618 \\
LAVI & -0.78 & -1.50 to -0.056 & 0.318 & 0.035 \\
LV mass & -0.49 & -0.94 to -0.04 & 0.319 & 0.035 \\
LVEF & 165 & -75 to 405 & 0.209 & 0.173 \\
S' & 10.2 & -6.66 to 27.14 & 0.185 & 0.228 \\
e' & 5.44 & -7.67 to 18.54 & 0.128 & 0.407 \\
E/e' & -7.53 & -13.81 to -1.24 & 0.349 & 0.020 \\
E/e* & -7.34 & -13.16 to -1.52 & 0.516 & 0.015 \\
\hline
\end{tabular}

BMI: body mass index; LAVI: normalized left atrium volume; LV: left ventricle; LVEF: LV ejection fraction; S': average systolic mitral annular motion; e': average diastolic mitral annular motion; E/e': mitral inflow E velocity to tissue Doppler e' ratio. *Adjusted by age. 
Table 3. Estimating quality of life in reduced ejection fraction heart failure patients from age, body mass index, exercise capacity, and echocardiography by simple linear regression.

\begin{tabular}{lccc}
\hline Variable & Coefficient & $95 \% \mathrm{Cl}$ & $\mathrm{R}$ \\
\hline Age & -0.414 & -1.03 to -0.203 & 0.204 \\
BMI & -0.10 & -2.38 to 0.197 & 0.255 \\
6MWT & -0.071 & -0.172 to 0.030 & 0.215 \\
LAVI & 0.274 & 0.036 to 0.513 & 0.095 \\
LV mass & 0.040 & -0.266 to 0.345 & 0.162 \\
LVEF & -23.3 & -104.7 to 58.1 & 0.040 \\
S' & -1.80 & -7.49 to 3.89 & 0.089 \\
e' & 1.38 & -2.44 to 5.21 & 0.795 \\
Ele' & 1.902 & -0.248 to 4.052 & 0.567 \\
\hline
\end{tabular}

BMI: body mass index; 6MWT: 6-minute walk test; LAVI: normalized left atrium volume; LV: left ventricle; LVEF: LV ejection fraction; S': average systolic mitral annular motion; e': average diastolic mitral annular motion; E/e': mitral inflow E velocity to tissue Doppler e' ratio.

authors have described associations between exercise capacity and diastolic function more accurately using tissue Doppler indexes (22-24). However, little is known about the association between diastolic function and quality of life and exercise capacity in optimally treated and compensated patients with systolic HF (11-13,22-24).

In the present study, although the LVEF and E/e' indexes were directly correlated, there was no association between LVEF and distance walked during the 6MWT, in accordance with others (25). On the other hand, walk distance was influenced by age and E/e'. Gardin et al. (13) also found a correlation between diastolic function and exercise tolerance in a large population of HF patients with reduced LVEF and NYHA functional class $\geqslant I$. In that study it was suggested that mitral valve $E / A$ and $E / e^{\prime}$ indexes were more strongly related to exercise performance than was LVEF. Brucks et al. (11) and Fukata and Little (12) showed that, regardless of LVEF and the severity of symptoms, the degree of diastolic dysfunction was closely associated with prognosis and exercise intolerance in $\mathrm{HF}$ patients in class $\geqslant 1 \mathrm{l}$. We included stable patients whose performance on the 6MWT suggested mild or moderate physical limitation. Despite the simplicity of the 6MWT, its use has been validated in the literature, because it can predict the exercise tolerance in patients with HF and reduced $\operatorname{LVEF}(26,27)$. Also, Carvalho et al. (28) showed a correlation between the 6MWT and cardiopulmonary exercise tests in patients with HF (NYHA I-II)

Our findings indicated that patients with systolic HF who are oligosymptomatic with pharmacologic treatment have a reduced physical capacity associated with decreased LV diastolic function. A possible explanation for our results is that physical activity increases heart rate, impairing atrial emptying and thus raising the pressure in the left atrium. These events would cause pulmonary congestion and exercise intolerance $(29,30)$. Diastolic function was evaluated using tissue Doppler imaging
(TDI) of mitral annular motion (E/e'). This index has been shown to be an excellent predictor of diastolic filling in subsets of patients. In addition, the TDI parameter that had the best correlation with the invasive mean LV diastolic pressure was the $\mathrm{E} / \mathrm{e}^{\prime}$ ratio; this correlation was better in patients with LVEF $<50 \%$ (14). Therefore, limitations on exercise would more likely be related to dyspnea caused by increased pressure in the left atrium than to a reduced oxygen supply related to decreased cardiac output.

Despite the evidence that LV function affects exercise capacity, reports indicate that ventricular function indexes do not affect a patient's reported quality of life (31). We found a positive association between LAVI and MLWHFQ scores. Specifically, the enlargement of the left atrium, indicating diastolic dysfunction, was associated with a higher MLWHFQ score, suggesting a decreased quality of life. We did not find a significant association between the systolic function index and the MLWHFQ score, in accordance with others $(6,32-34)$. On the contrary, there is a paucity of information on the association between quality of life and LAV or other index of diastolic function in HF patients with reduced LVEF.

It is worthy mentioning that $\mathrm{E} / \mathrm{e}^{\prime}$ did not correlate with quality of life and that LAVI did not correlate with walking distance. We believe that this asymmetry is caused by the variability of the indexes and the small number of patients included in the study. It is possible that, if we had a larger number of patients, then both indexes would be correlated with either quality of life or walking distance.

Interestingly, our results did not indicate a correlation between the MLWHFQ score and the 6MWT distance, indicating that diastolic dysfunction, rather than walk distance, plays a major role in decreasing quality of life. This finding is in contrast with those of other studies that used the same questionnaire $(34,35)$. A possible explanation for the disagreement is that the patients included in the earlier studies may have had more severe systolic 
dysfunction, further increasing LV filling pressure and reducing their 6MWT distance. Unfortunately, those studies did not evaluate diastolic function.

It is important to note that HF patients with systolic dysfunction and reduced cardiac output may have decreased respiratory and skeletal muscle performance, which would reduce their ability to perform exercise $(36,37)$. This condition decreases oxidative type I fibers and increases glycolytic type Ilb fibers. Other consequences that have been described include impaired endothelial function, negative changes in vasodilatory capacity, excessive sympathetic stimulation causing vasoconstriction, decreased blood flow to skeletal

\section{References}

1. Roger VL, Go AS, Lloyd-Jones DM, Benjamin EJ, Berry JD, Borden WB, et al. Executive summary: heart disease and stroke statistics - 2012 update: a report from the American Heart Association. Circulation 2012; 125: 188-197, doi: 10.1161/CIR.0b013e3182456d46.

2. Goldberg RJ, Ciampa J, Lessard D, Meyer TE, Spencer FA. Long-term survival after heart failure: a contemporary population-based perspective. Arch Intern Med 2007; 167: 490-496, doi: 10.1001/archinte.167.5.490.

3. Hunt SA, Baker DW, Chin MH, Cinquegrani MP, Feldman AM, Francis GS, et al. ACC/AHA guidelines for the evaluation and management of chronic heart failure in the adult: executive summary. A report of the American College of Cardiology/American Heart Association Task Force on Practice Guidelines (Committee to revise the 1995 Guidelines for the Evaluation and Management of Heart Failure). J Am Coll Cardiol 2001; 38: 2101-2113, doi: 10.1016/S0735-1097(01)01683-7.

4. Bittner V, Weiner DH, Yusuf S, Rogers WJ, Mclntyre KM, Bangdiwala SI, et al. Prediction of mortality and morbidity with a 6-minute walk test in patients with left ventricular dysfunction. SOLVD Investigators. JAMA 1993; 270: 17021707, doi: 10.1001/jama.1993.03510140062030.

5. Alahdab MT, Mansour IN, Napan S, Stamos TD. Six minute walk test predicts long-term all-cause mortality and heart failure rehospitalization in African-American patients hospitalized with acute decompensated heart failure. J Card Fail 2009; 15: 130-135, doi: 10.1016/j.cardfail.2008.10.006.

6. Morcillo C, Aguado O, Delas J, Rosell F. Utility of the Minnesota Living with Heart Failure Questionnaire for assessing quality of life in heart failure patients. Rev Esp Cardiol 2007; 60: 1093-1096, doi: 10.1157/13111242.

7. Alla F, Briancon S, Guillemin F, Juilliere Y, Mertes PM, Villemot JP, et al. Self-rating of quality of life provides additional prognostic information in heart failure. Insights into the EPICAL study. Eur J Heart Fail 2002; 4: 337-343, doi: 10.1016/S1388-9842(02)00006-5.

8. Kjaergaard J, Johnson BD, Pellikka PA, Cha SS, Oh JK, Ommen SR. Left atrial index is a predictor of exercise capacity in patients with hypertrophic cardiomyopathy. J Am Soc Echocardiogr 2005; 18: 1373-1380, doi: 10.1016/ j.echo.2005.05.020.

9. Okura H, Kubo T, Asawa K, Toda I, Yoshiyama M, muscles, and an enhanced ergoreflex response (38). In the present study, because these alterations were not evaluated, we are unable to draw conclusions concerning their effects on the patients' physical capacity.

We conclude that, despite the small number of patients, this study offers evidence that diastolic function is associated with physical capacity and quality of life and should be considered along with ejection fraction in patients with compensated systolic HF.

\section{Acknowledgments}

\section{Research supported by FAPESP (\#2009/50249-0).}

Yoshikawa J, et al. Elevated E/E' predicts prognosis in congestive heart failure patients with preserved systolic function. Circ J 2009; 73: 86-91, doi: 10.1253/circj.CJ-08-0457.

10. Smart N, Haluska B, Leano R, Case C, Mottram PM, Marwick TH. Determinants of functional capacity in patients with chronic heart failure: role of filling pressure and systolic and diastolic function. Am Heart J 2005; 149: 152-158, doi: 10.1016/j.ahj.2004.06.017.

11. Brucks S, Little WC, Chao T, Kitzman DW, WesleyFarrington D, Gandhi S, et al. Contribution of left ventricular diastolic dysfunction to heart failure regardless of ejection fraction. Am J Cardiol 2005; 95: 603-606, doi: 10.1016/ j.amjcard.2004.11.006.

12. Fukuta $\mathrm{H}$, Little WC. Contribution of systolic and diastolic abnormalities to heart failure with a normal and a reduced ejection fraction. Prog Cardiovasc Dis 2007; 49: 229-240, doi: 10.1016/j.pcad.2006.08.009.

13. Gardin JM, Leifer ES, Fleg JL, Whellan D, Kokkinos P, Leblanc $\mathrm{MH}$, et al. Relationship of DopplerEchocardiographic left ventricular diastolic function to exercise performance in systolic heart failure: the HFACTION study. Am Heart J 2009; 158: S45-S52, doi: 10.1016/j.ahj.2009.07.015.

14. Ommen SR, Nishimura RA, Appleton CP, Miller FA, Oh JK, Redfield MM, et al. Clinical utility of Doppler echocardiography and tissue Doppler imaging in the estimation of left ventricular filling pressures: A comparative simultaneous Doppler-catheterization study. Circulation 2000; 102: 17881794, doi: 10.1161/01.CIR.102.15.1788.

15. Tamura H, Watanabe T, Nishiyama S, Sasaki S, Arimoto T, Takahashi $\mathrm{H}$, et al. Increased left atrial volume index predicts a poor prognosis in patients with heart failure. $J$ Card Fail 2011; 17: 210-216, doi: 10.1016/j.cardfail.2010.10.006.

16. Redfield MM, Jacobsen SJ, Burnett JC Jr, Mahoney DW, Bailey KR, Rodeheffer RJ. Burden of systolic and diastolic ventricular dysfunction in the community: appreciating the scope of the heart failure epidemic. JAMA 2003; 289: 194202, doi: 10.1001/jama.289.2.194.

17. Lang RM, Bierig M, Devereux RB, Flachskampf FA, Foster E, Pellikka PA, et al. Recommendations for chamber quantification. Eur J Echocardiogr 2006; 7: 79-108, doi: 10.1016/j.euje.2005.12.014. 
18. Nagueh SF, Appleton CP, Gillebert TC, Marino PN, Oh JK, Smiseth OA, et al. Recommendations for the evaluation of left ventricular diastolic function by echocardiography. Eur $\mathrm{J}$ Echocardiogr 2009; 10: 165-193, doi: 10.1093/ejechocard/ jep007.

19. Rector TS, Kubo SH, Cohn JN. Patient's self-assessment of their congestive heart failure. Part 2: Content, reliability and validity of a new measure, the Minnesota Living with Heart Failure Questionnaire. Heart Failure 1987; 3: 198-207.

20. Carvalho VO, Guimaraes GV, Carrara D, Bacal F, Bocchi EA. Validation of the Portuguese version of the Minnesota Living with Heart Failure Questionnaire. Arq Bras Cardiol 2009; 93: 39-44, doi: 10.1590/S0066-782X2009000700008.

21. ATS statement: guidelines for the six-minute walk test. $A m \mathrm{~J}$ Respir Crit Care Med 2002; 166: 111-117, doi: 10.1164/ ajrccm.166.1.at1102.

22. Acarturk E, Koc M, Bozkurt A, Unal I. Left atrial size may predict exercise capacity and cardiovascular events in patients with heart failure. Tex Heart Inst J 2008; 35: 136-143.

23. Yoshino T, Nakae I, Matsumoto T, Mitsunami K, Horie M. Relationship between exercise capacity and cardiac diastolic function assessed by time-volume curve from 16-frame gated myocardial perfusion SPECT. Ann Nucl Med 2010; 24: 469-476, doi: 10.1007/s12149-010-0382-x.

24. Saura D, Marin F, Climent V, Gonzalez J, Roldan V, Hernandez-Romero D, et al. Left atrial remodelling in hypertrophic cardiomyopathy: relation with exercise capacity and biochemical markers of tissue strain and remodelling. Int J Clin Pract 2009; 63: 1465-1471, doi: 10.1111/ j.1742-1241.2009.02127.x.

25. Donal E, Raud-Raynier P, de Place C, Gervais R, Rosier A, Roulaud $M$, et al. Resting echocardiographic assessments of left atrial function and filling pressure interest in the understanding of exercise capacity in patients with chronic congestive heart failure. J Am Soc Echocardiogr 2008; 21: 703-710, doi: 10.1016/j.echo.2007.10.002.

26. Cahalin LP, Mathier MA, Semigran MJ, Dec GW, DiSalvo TG. The six-minute walk test predicts peak oxygen uptake and survival in patients with advanced heart failure. Chest 1996; 110: 325-332, doi: 10.1378/chest.110.2.325.

27. Daullxhiu I, Haliti E, Poniku A, Ahmeti A, Hyseni V, Olloni R, et al. Predictors of exercise capacity in patients with chronic heart failure. J Cardiovasc Med 2011; 12: 223-225.

28. Carvalho EE, Costa DC, Crescencio JC, Santi GL, Papa V, Marques $F$, et al. Heart failure: comparison between sixminute walk test and cardiopulmonary test. Arq Bras Cardiol 2011; 97: 59-64, doi: 10.1590/S0066-782X2011005000056.
29. Little WC, Kitzman DW, Cheng CP. Diastolic dysfunction as a cause of exercise intolerance. Heart Fail Rev 2000; 5: 301-306, doi: 10.1023/A:1026503028065.

30. McMurray JJ, Adamopoulos S, Anker SD, Auricchio A, Bohm M, Dickstein K, et al. ESC Guidelines for the diagnosis and treatment of acute and chronic heart failure 2012: The Task Force for the Diagnosis and Treatment of Acute and Chronic Heart Failure 2012 of the European Society of Cardiology. Developed in collaboration with the Heart Failure Association (HFA) of the ESC. Eur Heart $J$ 2012; 33: 1787-1847, doi: 10.1093/eurheartj/ehs104.

31. Grady KL, Jalowiec A, White-Williams C, Pifarre R, Kirklin $\mathrm{JK}$, Bourge RC, et al. Predictors of quality of life in patients with advanced heart failure awaiting transplantation. $J$ Heart Lung Transplant 1995; 14: 2-10.

32. Parajon T, Lupon J, Gonzalez B, Urrutia A, Altimir S, Coll R, et al. Use of the Minnesota Living with Heart Failure Quality of Life Questionnaire in Spain. Rev Esp Cardiol 2004; 57: 155-160.

33. Riegel B, Moser DK, Glaser D, Carlson B, Deaton C, Armola $R$, et al. The Minnesota Living with Heart Failure Questionnaire: sensitivity to differences and responsiveness to intervention intensity in a clinical population. Nurs Res 2002; 51: 209-218, doi: 10.1097/00006199-200207000-00001.

34. Quittan M, Wiesinger GF, Crevenna R, Nuhr MJ, Posch M, Hulsmann $M$, et al. Cross-cultural adaptation of the Minnesota Living with Heart Failure Questionnaire for German-speaking patients. J Rehabil Med 2001; 33: 182186, doi: 10.1080/165019701750300654.

35. Green CP, Porter CB, Bresnahan DR, Spertus JA Development and evaluation of the Kansas City Cardiomyopathy Questionnaire: a new health status measure for heart failure. J Am Coll Cardiol 2000; 35: 12451255, doi: 10.1016/S0735-1097(00)00531-3.

36. Sbruzzi G, Ribeiro RA, Schaan BD, Signori LU, Silva AM, Irigoyen MC, et al. Functional electrical stimulation in the treatment of patients with chronic heart failure: a metaanalysis of randomized controlled trials. Eur J Cardiovasc Prev Rehabil 2010; 17: 254-260.

37. Wong E, Selig S, Hare DL. Respiratory muscle dysfunction and training in chronic heart failure. Heart Lung Circ 2011; 20: 289-294, doi: 10.1016/j.hlc.2011.01.009.

38. Pina IL, Apstein CS, Balady GJ, Belardinelli R, Chaitman BR, Duscha BD, et al. Exercise and heart failure: A statement from the American Heart Association Committee on exercise, rehabilitation, and prevention. Circulation 2003; 107: 12101225, doi: 10.1161/01.CIR.0000055013.92097.40. 